\title{
DNA sequence polymorphism of Pup1 linked K20-1 STS region can be effectively used in molecular breeding of rice for phosphorus deficiency tolerance
}

\author{
Y.C. Aluwihare ${ }^{1,2}$, M.D.M. Chamikara ${ }^{1}$, D.R.R.P. Dissanayake ${ }^{1}$, M.D.M.I.M. Dissanayake ${ }^{1}$, \\ N.N.H. Karannagoda ${ }^{1}$, A.G.M.L.K. Dayananda ${ }^{1}$, D.N. Sirisena ${ }^{3}$, W.L.G. Samarasinghe ${ }^{3}$, R.G.S.C. \\ Rajapakse $^{1,2}$ and S.D.S.S. Sooriyapathirana ${ }^{1,2^{*}}$ \\ ${ }^{1}$ Department of Molecular Biology and Biotechnology, Faculty of Science, University of Peradeniya, Peradeniya. \\ ${ }^{2}$ Postgraduate Institute of Science, University of Peradeniya, Peradeniya. \\ ${ }^{3}$ Rice Research and Development Institute, Bathalagoda, Ibbagamuwa.
}

Revised: 16 June 2017; Accepted: 20 July 2017

\begin{abstract}
Pupl is the major quantitative trait locus (QTL) for phosphorus deficiency (PD) tolerance in rice. The molecular markers linked to Pupl are available for numerous rice genotypes. However, novel haplotypes of Pupl could be detected if specific landraces are subjected to genetic analyses. A set of 30 local rice genotypes were assessed for PD tolerance and in the present study, they were characterised by sequencing K20-1, a co-dominant locus within the Pupl locus. The DNA polymorphism was also checked for the association with PD tolerance. A total of 10 SNPs and one INDEL were discovered among the 32 genotypes including Kasalath and Nipponbare as $\mathrm{PD}$ tolerant and sensitive reference rice varieties, respectively. Four unique SNPs were discovered in the studied germplasm that are not present in either Kasalath or Nipponbare. The SNP located at the $209^{\text {th }}$ position was very important as it is unique to highly PD tolerant landraces Murungakayan and Suduheenati, and varieties H-4, H-7 and H-10. These five genotypes lack the INDEL region present in Kasalath highlighting the presence of novel Pup 1 haplotypes in country specific rice varieties/ landraces, and they can be used as parental genotypes to introduce PD tolerance into new varieties in rice breeding programmes in Sri Lanka.
\end{abstract}

Keywords: K20-1, marker assisted breeding, OsPupK20-2, phosphorus deficiency tolerance, Pup1, rice landraces.

\section{INTRODUCTION}

Phosphorus $(\mathrm{P})$ is one of the key limiting nutrients that can significantly affect profitable rice farming (Fageria et al., 1982; Hedley et al., 1994; Kirk et al., 1998). The application of artificial $\mathrm{P}$ fertiliser is very expensive, which could also contribute to environmental pollution and health hazards (Bennett et al., 2001; Cordell et al., 2009; Chandrajith et al., 2010; Jiao et al., 2012). The development of improved rice varieties that can perform well under low P regimes using marker assisted breeding (MAB) is identified as the most promising and sustainable solution to tackle these problems (Wissuwa, 2003). Although MAB programmes for $P$ deficiency (PD) tolerance are not yet routinely employed in rice breeding, many physiological and genomic studies have been carried out. PD tolerant and sensitive rice landraces and improved varieties have been identified in countries such as China (Li et al., 2009), the Philippines (Heuer et al., 2009), Indonesia (Prasetiyono et al., 2010), India (Tyagi et al., 2012) and Sri Lanka (Aluwihare et al., 2016). The genomic basis of PD tolerance has been subjected to intense studies and a quantitative trait locus

* Corresponding author (sunethssuop@gmail.com; iD https://orcid.org/0000-0002-5592-1742) 
(QTL), Pup1, with a major effect, has been identified on rice chromosome 12. Another QTL with a minor effect was also identified, which is located on chromosome 6 (Wissuwa et al., 1998). These QTLs have been initially detected using a drought and PD tolerant rice landrace, Kasalath and later validated using a PD sensitive landrace Nipponbare derived near-isogenic lines (NILs) (Wissuwa \& Ae, 2001; Wissuwa et al., 2002). It was reported that the increasing alleles/haplotypes of Pup1 could increase the yield by two- to four-fold (Wissuwa, 2003), which is a significant reward in rice farming if put into the practice through MAB. The mechanism of PD tolerance conferred by Pupl has been further studied (Wissuwa, 2005; Yi et al., 2005; Gamuyao et al., 2012) and the differences of the root surfaces were characterised among the tolerant and sensitive rice genotypes (Wissuwa, 2003; Wissuwa et al., 2005). It was found that Pup1 is co-segregating with the external efficiency of P uptake (Wissuwa, 2005). A larger effect of Pup1 conferred tolerance is mainly found to act on roots and the candidate genes within the Pupl region were also identified (Heuer et al., 2009; Chin et al., 2011). In addition to PD tolerance, Pupl was also reported to confer drought tolerance in rice (Ismail et al., 2007; Chin et al., 2011). Many attempts have been made to develop molecular markers linked to Pupl region that can be used in MAB (Heuer et al., 2009; Chin et al., 2010; Chin et al., 2011). Pariasca-Tanaka et al. (2014) have developed an allele specific marker to transfer Pstoll gene (coding for a Pupl specific protein kinase present only in PD tolerant genotypes) from the donor parent Kasalath to PD sensitive African rice varieties. A marker haplotype analysis for Pup1 region has been conducted using a set of rice germplasm available in India (Tyagi et al., 2012). However, the most comprehensive genomic analysis of Pupl was conducted by Chin et al. (2011) and they developed molecular markers that could be used to detect allelic haplotypes and associated sequence polymorphisms. Furthermore, comprehensive bioinformatic and functional genomic studies on the key genes identified within the Pupl locus were also conducted (Yi et al., 2005; Chin et al., 2011; Gamuyao et al., 2012). However, many promising landraces and improved varieties were not included as the sources for mapping in those studies.

Recently a set of PD screening results of a selected panel of germplasm including landraces and improved rice varieties in Sri Lanka was published (Aluwihare et al., 2016). The present study was conducted to identify whether the genotypes studied by Aluwihare et al. (2016) contain similar or different haplotypes to that of PD tolerant Kasalath or sensitive Nipponbare landraces using the co-dominant, easily amplifiable and polymorphic K20-1 locus of the Pupl genomic region reported in Chin et al. (2011). The associations between DNA sequence polymorphism within the K20-1 region and PD tolerance related traits were also examined to establish a basis for MAB of rice.

\section{METHODOLOGY}

\section{Rice genotypes and assessment of PD tolerance}

A total of 30 rice genotypes (Table 1) including landraces and improved varieties obtained from the Rice Research and Development Institute (RRDI), Bathalagoda, Sri Lanka were used in the present study. The plants were grown under $\mathrm{P}_{0}$ [using the ultisol soil (1 $\mathrm{mg}$ of $\mathrm{P}$ in a $\mathrm{kg}$ of soil) at RRDI, which has not been fertilised for the last 40 years (Kumaragamage \& Indraratne, 2011)] and $\mathrm{P}_{30}$ [recommended $\mathrm{P}$ fertiliser application rate $(30 \mathrm{mg}$ of $\mathrm{P}_{2} \mathrm{O}_{5}$ was added to $1 \mathrm{~kg}$ of ultisol soil)] conditions under two main annual cropping seasons in Sri Lanka: Yala and Maha seasons (DOA, 2006a). The experiments were conducted under greenhouse and field conditions in 2012.

\section{Growth parameters}

Plant height $(\mathrm{PlH})$ was measured from the base of the plant to its top using a meter ruler. The number of tillers (NT) was counted. PlH and NT data were recorded at the flowering stage of each genotype. Shoot dry weight (SDW) was obtained from the shoots of the plants harvested at the same stage. The shoots were briefly rinsed with distilled water and oven dried at $60^{\circ} \mathrm{C}$.

\section{Trait related to $\mathbf{P}$ deficiency tolerance}

\section{Shoot P concentration (SPC)}

Finely ground shoot material was liquefied in a solution containing $1 \mathrm{HNO}_{3}: 3 \mathrm{HClO}_{4}: 1 \mathrm{H}_{2} \mathrm{SO}_{4}$ and shoot $\mathrm{P}$ concentration (SPC) (mg of $\mathrm{P} / \mathrm{g}$ of shoot dry matter) was determined according to the phosphovanadate procedure (Hanson, 1950).

\section{Shoot P uptake (SPU)}

Shoot P uptake (SPU) was calculated according to the formula explained in Fageria et al. (1988) and Gunes et al. (2006). The SPU was calculated collectively for whole four plants grown in the pot.

\section{P utilisation efficiency (PUE)}

$P$ utilisation efficiency (PUE) was calculated as the biomass produced per unit $\mathrm{P}$ accumulated in the shoot tissue. 
Table 1: Rice genotypes characterised for the DNA sequence polymorphism in K20-1 locus

\begin{tabular}{|c|c|c|}
\hline Type of cultivar & Name of the genotype ${ }^{a}$ & PD tolerance score ${ }^{b}$ \\
\hline \multirow[t]{12}{*}{ Landrace } & Suwandel & 2 \\
\hline & Murungakayan & 3 \\
\hline & Sudubalawee & 3 \\
\hline & Suduheenati & 2 \\
\hline & Hondarawala & 2 \\
\hline & Marss $^{e}$ & 3 \\
\hline & Kokuwellai & 3 \\
\hline & Kaluheenati & 3 \\
\hline & Pokkali & 2 \\
\hline & Rathuheenati & 2 \\
\hline & Rathel & 3 \\
\hline & Sudurusamba & 2 \\
\hline \multirow[t]{3}{*}{ Old improved varieties ${ }^{c}$} & $\mathrm{H}-10$ & 3 \\
\hline & $\mathrm{H}-4$ & 3 \\
\hline & $\mathrm{H}-7$ & 3 \\
\hline \multirow[t]{15}{*}{ Newly improved varieties ${ }^{d}$} & At 353 & 2 \\
\hline & At 306 & 1 \\
\hline & At 362 & 3 \\
\hline & At 354 & 1 \\
\hline & $\mathrm{Bg} 403$ & 3 \\
\hline & $\mathrm{Bg} 250$ & 2 \\
\hline & $\mathrm{Bg} 358$ & 2 \\
\hline & $\mathrm{Bg} 357$ & 1 \\
\hline & $\mathrm{Bg} 300$ & 1 \\
\hline & $\mathrm{Bg} 450$ & 2 \\
\hline & Bg 94-1 & 3 \\
\hline & $\mathrm{Bg} 352$ & 2 \\
\hline & Bg 379-2 & 2 \\
\hline & Bw 364 & 2 \\
\hline & Ld 356 & 2 \\
\hline \multicolumn{3}{|c|}{$\begin{array}{l}\text { a Standard rice variety names as given in the Database of Rice Varieties, Department of Agriculture, } \\
\text { Sri Lanka (2006b) } \\
\text { b PD tolerance scores are indicated as described in Aluwihare et al. (2016). 3: Tolerant; } \\
\text { 2: moderately tolerant; } 1 \text { : sensitive } \\
{ }^{\text {c }} \text { Rice varieties developed before } 1970 \\
{ }^{d} \text { Rice varieties developed after } 1970\end{array}$} \\
\hline
\end{tabular}

The performance of each genotype to $\mathrm{P}$ starvation was evaluated and analysed using multiple regression procedures to assign overall PD tolerance scores to each genotype (Aluwihare et al., 2016) (Table 1). The same dataset was used in the current study for association analyses.

\section{PCR and DNA sequencing}

Leaf samples were collected from each rice genotype and the DNA was extracted using Dneasy ${ }^{\circledR}$ plant mini kit (Qiagen, Solna, Sweden). The DNA was PCR amplified using K20-1 locus specific forward
(5'TCAGGTGATGGGAATCATTG3') and reverse (5'TGTTCCAACCAAACAACCTG3') primers (Chin et al., 2011) using a thermal cycler (Takara, Japan). The PCR cycle consisted of an initial denaturation step at $94{ }^{\circ} \mathrm{C}$ for $5 \mathrm{~min}$, followed by 35 cycles of $94^{\circ} \mathrm{C}$ for $30 \mathrm{~s}$, $55^{\circ} \mathrm{C}$ for $90 \mathrm{~s}$, and $72{ }^{\circ} \mathrm{C}$ for $2 \mathrm{~min}$, and a final extension step of $72{ }^{\circ} \mathrm{C}$ for $10 \mathrm{~min}$. PCR products were visualised using $1 \%$ agarose gel electrophoresis and purified using Wizard SV gel ${ }^{\circledR}$ and PCR clean-up system (Promega Corporation, Madison, Wisconsin, USA). The purified PCR products were cycle sequenced using a Sanger Sequencing based ABI 3500 Series Genetic Analyser (Applied Biosystems ${ }^{\circledR}$ ). 


\section{Data analysis}

\section{Sequence alignment}

As reference DNA sequences of K20-1, the GenBank entry for Kasalath (AB458444.1) (PD tolerant genotype) and Nipponbare (AP014968.1) (PD sensitive genotype) (www.ncbi.nlm.nih.gov/genbank/) were used. The K20-1 DNA sequences of the 32 rice genotypes (including two reference sequences) were aligned using Clustal Omega software (http://www.ebi.ac.uk). The SNP and INDEL positions were identified and their allelic states were recorded for each genotype. The part of the exon 2 in OsPupK20-2 gene falling within the K20-1 region was translated to amino acid sequence and subjected to multiple sequence analysis using Clustal Omega.

\section{Assessment and visualisation of DNA polymorphism}

The polymorphic SNPs and INDEL present in 32 rice genotypes were subjected to cluster analysis and dendrogram construction using the statistical package Minitab 16 (Minitab Inc., USA). Clustering details of the genotypes were compared with the PD tolerance score data of the same genotypes published in Aluwihare et al. (2016).

\section{Visualisation of identical by descent haplotypes and PD tolerance scores}

The K20-1 haplotypes of the genotypes were visualised using Pedimap software (Voorrips, 2007) to show the inheritance of haplotypes, identical by descent (IBD) probabilities and PD tolerance scores.

\section{Analysis of the association between sequence polymorphism and PD tolerance traits}

The PD tolerance screening data, PlH, NT, SDW, SPC, SPU and PUE, of the 30 rice genotypes were subjected to SNP/INDEL association analyses employing the GLM procedure in Tassel 5 software (Bradbury et al., 2007). The mean differences between the phenotypic classes of the counter path SNP/INDEL alleles were also calculated.

\section{RESULTS AND DISCUSSION}

The identification of QTL and the establishment of numerous QTL haplotypes associated with varying degrees of the trait value are very important to initiate MAB for complex traits (He et al., 2006; Ducrocq et al., 2009; Li et al., 2012). The Pup1 QTL is molecularly characterised (Ni et al., 1998; Wissuwa et al., 1998; Lang \& Buu, 2006; Prasetiyono et al., 2010) in which associated haplotypes (Chin et al., 2011; Tyagi et al., 2012) and some of the underline genes are characterised (Chin et al., 2011; Gamuyao et al., 2012). However, many of the country and geographical location specific rice landraces and important varieties have not been included in genetic and physiological studies on PD tolerance. Many studies (Wissuwa \& Ae, 2001; Chin et al., 2011; Gamuyao et al., 2012) have highlighted the importance of using tolerant landraces and hardy varieties to mine the interested alleles and haplotypes for MAB. Having the broader aim of establishing a comprehensive marker assisted rice breeding programme in Sri Lanka, a set of 30 rice genotypes containing landraces and improved varieties were characterised for PD tolerance (Aluwihare et al., 2016).

\section{Sequence alignment and analysis of polymorphism}

The studied rice genotypes were characterised for 46 DNA markers developed for the Pupl region in previous studies (Heuer et al., 2009; Chin et al., 2010; Chin et al., 2011). The K20-1 STS region was selected for the present study and subjected to DNA sequence analysis. The K20-1 region was chosen because of its co-dominant nature, easy and non-ambiguous amplification and the presence of significant polymorphism (Chin et al., 2011). PCR amplification of genomic DNA using K20-1 primers yielded a band with an approximate size of $240 \mathrm{bp}$. When K20-1 DNA sequences (Table 2) of all 32 rice genotypes were aligned, a biallelic length polymorphism was detected where a 240 base long fragment was observed in 11 genotypes and a 243 base long fragment was observed in the other 21 genotypes. A total 11 nucleotide variations detected comprised 10 SNPs (nine transition and one transversion mutations) and one INDEL; and all of them were biallelic and consistent with the sequence information reported in Chin et al. (2011). Six SNPs were observed as reported in Chin et al. (2011) where either Kasalath-like or Nipponbare-like alleles were present (the SNPs found at $56^{\text {th }}, 158^{\text {th }}, 193^{\text {rd }}, 198^{\text {th }}, 210^{\text {th }}$ and $212^{\text {th }}$ positions). Novel SNP alleles were detected for the $64^{\text {th }}, 70^{\text {th }}, 106^{\text {th }}$ and $209^{\text {th }}$ base positions where Kasalath, Nipponbare and some of the Sri Lankan rice genotypes shared one SNP allele, and other Sri Lankan rice genotypes shared a different allele. The SNP found at the $209^{\text {th }}$ position is particularly interesting as highly PD tolerant rice genotypes Murungakayan, Suduheenati, $\mathrm{H}-4, \mathrm{H}-7$ and H-10 have SNP allele 'A', whereas Kasalath and Nipponbare and other 26 Sri Lankan genotypes shared a common allele ' $G$ ' showing the presence of a transition mutation (Figure 1). 
The three-base difference was due to the 'CAG' INDEL present in the position between $204^{\text {th }}$ to $206^{\text {th }}$ nucleotides. According to Chin et al. (2011), this INDEL is present in Kasalath and significantly associated with PD tolerance. Accordingly the same INDEL was detected in nine genotypes in the present study and according to Aluwihare et al. (2016) these genotypes are either tolerant or moderately tolerant to PD. However, it is

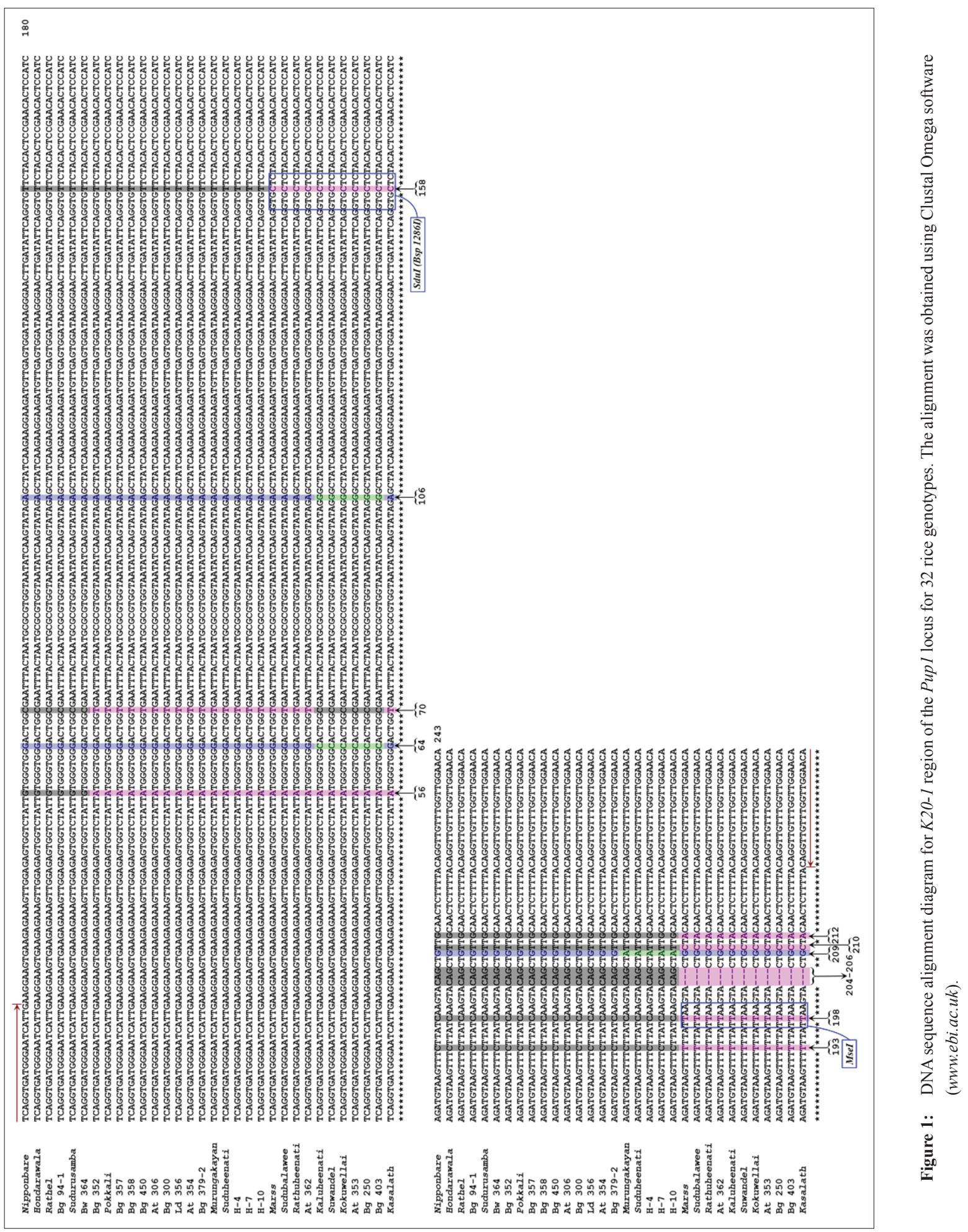


interesting to note that this INDEL was absent in the PD tolerant genotypes Murungakayan, Suduheenati, $\mathrm{H}-4, \mathrm{H}-7$ and H-10 implying that PD tolerance was not always associated with this INDEL. The two restriction sites SduI (Bsp 1286I) and MseI reported in Chin et al. (2011) are also observed in the present study in 10 tolerant or moderately tolerant genotypes (Figure 1).

\begin{tabular}{|c|c|}
\hline Nipponbare & QVMGIIEGSEEKVGEWSIVGGTGEFTNARGNIKYRAIKKEDVEWIRELDIQVFYTPNTPSDV 62 \\
\hline Hondarawala & QVMGI IEGSEEKVGEWSIVGGTGEFTNARGNIKYRAIKKEDVEWIRELDIQVFYTPNTPSDV \\
\hline Rathel & QVMGI IEGSEEKVGEWSIVGGTGEFTNARGNIKYRAI KKEDVEWIRELDIQVFYTPNTPSDV \\
\hline Bg 94-1 & QVMGIIEGSEEKVGEWSIVGGTGEFTNARGNIKYRAIKKEDVEWIRELDIQVFYTPNTPSDV \\
\hline Sudurusamba & QVMGIIEGSEEKVGEWSIVGGTGEFTNARGNIKYRAIKKEDVEWIRELDIQVFYTPNTPSDV \\
\hline Bw 364 & QVMGI IEGSEEKVGEWSIVGGTGEFTNARGNIKYRAIKKEDVEWIRELDIQVFYTPNTPSDV \\
\hline Bg 352 & QVMGIIEGSEEKVGEWSIMGGTGEFTNARGNIKYRAIKKEDVEWIRELDIQVFYTPNTPSDV \\
\hline Pokkali & QVMGI IEGSEEKVGEWSIMGGTGEFTNARGNIKYRAIKKEDVEWIRELDIQVFYTPNTPSDV \\
\hline Bg 357 & QVMGIIEGSEEKVGEWSIMGGTGEFTNARGNIKYRAIKKEDVEWIRELDIQVFYTPNTPSDV \\
\hline Bg 358 & QVMGI IEGSEEKVGEWSIMGGTGEFTNARGNIKYRAI KKEDVEWIRELDIQVFYTPNTPSDV \\
\hline Bg 450 & QVMGIIEGSEEKVGEWSIMGGTGEFTNARGNIKYRAIKKEDVEWIRELDIQVFYTPNTPSDV \\
\hline At 306 & QVMGI IEGSEEKVGEWSIMGGTGEFTNARGNIKYRAIKKEDVEWIRELDIQVFYTPNTPSDV \\
\hline Bg 300 & QVMGI IEGSEEKVGEWSIMGGTGEFTNARGNIKYRAIKKEDVEWIRELDIQVFYTPNTPSDV \\
\hline Ld 356 & QVMGI IEGSEEKVGEWSIMGGTGEFTNARGNIKYRAIKKEDVEWIRELDIQVFYTPNTPSDV \\
\hline At 354 & QVMGI IEGSEEKVGEWSIMGGTGEFTNARGNIKYRAIKKEDVEWIRELDIQVFYTPNTPSDV \\
\hline Bg 379-2 & QVMGI IEGSEEKVGEWSIMGGTGEFTNARGNIKYRAIKKEDVEWIRELDIQVFYTPNTPSDV \\
\hline Murungakayan & QVMGI IEGSEEKVGEWSIMGGTGEFTNARGNIKYRAIKKEDVEWIRELDIQVFYTPNTPSDV \\
\hline Suduheenati & QVMGI IEGSEEKVGEWSIMGGTGEFTNARGNIKYRAIKKEDVEWIRELDIQVFYTPNTPSDV \\
\hline $\mathrm{H}-4$ & QVMGI IEGSEEKVGEWSIMGGTGEFTNARGNIKYRAIKKEDVEWIRELDIQVFYTPNTPSDV \\
\hline $\mathrm{H}-7$ & QVMGI IEGSEEKVGEWSIMGGTGEFTNARGNIKYRAIKKEDVEWIRELDIQVFYTPNTPSDV \\
\hline $\mathrm{H}-10$ & QVMGI IEGSEEKVGEWSIMGGTGEFTNARGNIKYRAI KKEDVEWIRELDIQVFYTPNTPSDV \\
\hline Marss & QVMGI IEGSEEKVGEWSIMGGTGEFTNARGNIKYRAIKKEDVEWIRELDIQVLYTPNTPSDV \\
\hline Sudubalawee & QVMGI IEGSEEKVGEWSIMGGTGEFTNARGNIKYRAIKKEDVEWIRELDIQVLYTPNTPSDV \\
\hline Rathuheenati & QVMGI IEGSEEKVGEWSIMGGTGEFTNARGNIKYRAIKKEDVEWIRELDIQVLYTPNTPSDV \\
\hline At 362 & QVMGI IEGSEEKVGEWSIMGGTGEFTNARGNIKYRAIKKEDVEWIRELDIQVLYTPNTPSDV \\
\hline Kaluheenati & QVMGI IEGSEEKVGEWSIMGGTGEFTNARGNIKYRAIKKEDVEWIRELDIQVLYTPNTPSDV \\
\hline Suwandel & QVMGIIEGSEEKVGEWSIMGGTGEFTNARGNIKYRAIKKEDVEWIRELDIQVLYTPNTPSDV \\
\hline Kokuwellai & QVMGI IEGSEEKVGEWSIMGGTGEFTNARGNIKYRAI KKEDVEWIRELDIQVLYTPNTPSDV \\
\hline At 353 & QVMGI IEGSEEKVGEWSIMGGTGEFTNARGNIKYRAIKKEDVEWIRELDIQVLYTPNTPSDV \\
\hline $\mathrm{Bg} 250$ & QVMGI IEGSEEKVGEWSIMGGTGEFTNARGNIKYRAIKKEDVEWIRELDIQVLYTPNTPSDV \\
\hline $\mathrm{Bg} 403$ & QVMGI IEGSEEKVGEWSIMGGTGEFTNARGNIKYRAIKKEDVEWIRELDIQVLYTPNTPSDV \\
\hline Kasalath & 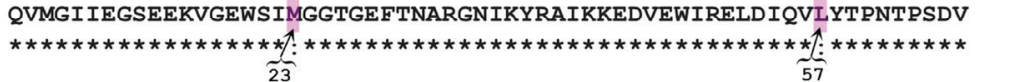 \\
\hline
\end{tabular}

Figure 2: Protein sequence alignment diagram for the portion of dirigent-like model gene (OsPupK20-2) fallen within the $K 20-1$ STS region of the 32 rice genotypes

Biallelic polymorphism was detected in all the SNPs and INDEL loci showing a limited level of heterozygosity present across the 32 rice genotypes tested. K20-1 DNA sequences of the 32 rice genotypes (Figure 1) were translated to amino acid sequences with the relevant reading frame and only two amino acid changes were observed, in which valine to methionine mutation was at $19^{\text {th }}$ position and phenylalanine to leucine mutation was at $53^{\text {rd }}$ position (Figure 2).

\section{Cluster analysis based on sequence polymorphism}

Sequence polymorphism detected in the K20-1 region of the 32 rice genotypes was subjected to cluster analysis and dendrogram construction. At $22.54 \%$ of sequence similarity level, two clusters were formed. One of these two clusters were further divided into two sub clusters named $\mathrm{C} 1$ and $\mathrm{CK}$ (K stands for Kasalath type) at a similarity level of $45.23 \%$. The other cluster formed at $22.54 \%$ similarity got further divided into two sub clusters at $55.28 \%$ similarity. Out of these two clusters, one cluster was not further collapsed and labelled as $\mathrm{CN}$ (N stands for Nipponbare type) and the other cluster was collapsed at a similarity level of $68.37 \%$ into two clear clusters that were labelled as C2 and C3. Unique haplotypes were observed for each cluster. The genotypes in clusters $\mathrm{C} 2, \mathrm{C} 3$ and $\mathrm{CN}$ contained the insertion ' $\mathrm{CAG}$ ' and the genotypes in other clusters contained the deletion (i.e. 'CAG' was missing) (Figure 3).

Cluster CK designates the genotypes, which has $100 \%$ similarity to the K20-1 region of the Kasalath 
genotype. The improved variety At 362 , PD tolerant landraces Sudubalawee, Marss, and the moderately tolerant landrace Rathuheenati have identical K20-1 regions to that of Kasalath. Cluster CN, the Nipponbare like cluster, contains two PD tolerant genotypes Bg 94-1 and Rathel, and moderately tolerant genotypes $\mathrm{Bw}$ 364, Sudurusamba and Hondarawala. However, no PD sensitive genotypes were observed within the $\mathrm{CN}$ cluster indicating the genetic complexity and the fact that Nipponbare type haplotype cannot always be used in MAB as the indicator haplotype of PD sensitivity. It also implies that a different PD sensitive mechanism could be present in Sri Lankan rice genotypes than that of Nipponbare. The cluster $\mathrm{C} 1$ contains three tolerant genotypes, Bg 403, Kokuwellai and Kaluheenati, and moderately tolerant genotypes $\mathrm{Bg} 250$, At 353 and Suwandel. Cluster C2 contains only extremely tolerant H-4, H-7, H-10, Murungakayan and Suduheenati and could be considered as the PD tolerant cluster in the studied germplasm. Cluster C3 has six moderately tolerant genotypes and four sensitive genotypes. All the sensitive genotypes detected in Aluwihare et al. (2016) are stacked within cluster C3 (Figure 3).

\section{Pedigree analysis}

Visualisation of pedigrees with respect to parental relationships, trait values and marker genotypes/ haplotypes are very important in making decisions for breeding and genetic studies. Voorrips (2007) has developed a software called Pedimap, which could be employed efficiently and meaningfully to display such information to be easily used in breeding programmes. Pedimap based pedigree displays have been particularly used in Rosaceae research community (Rosyara et al., 2013; Peace et al., 2014) and can be used in rice research

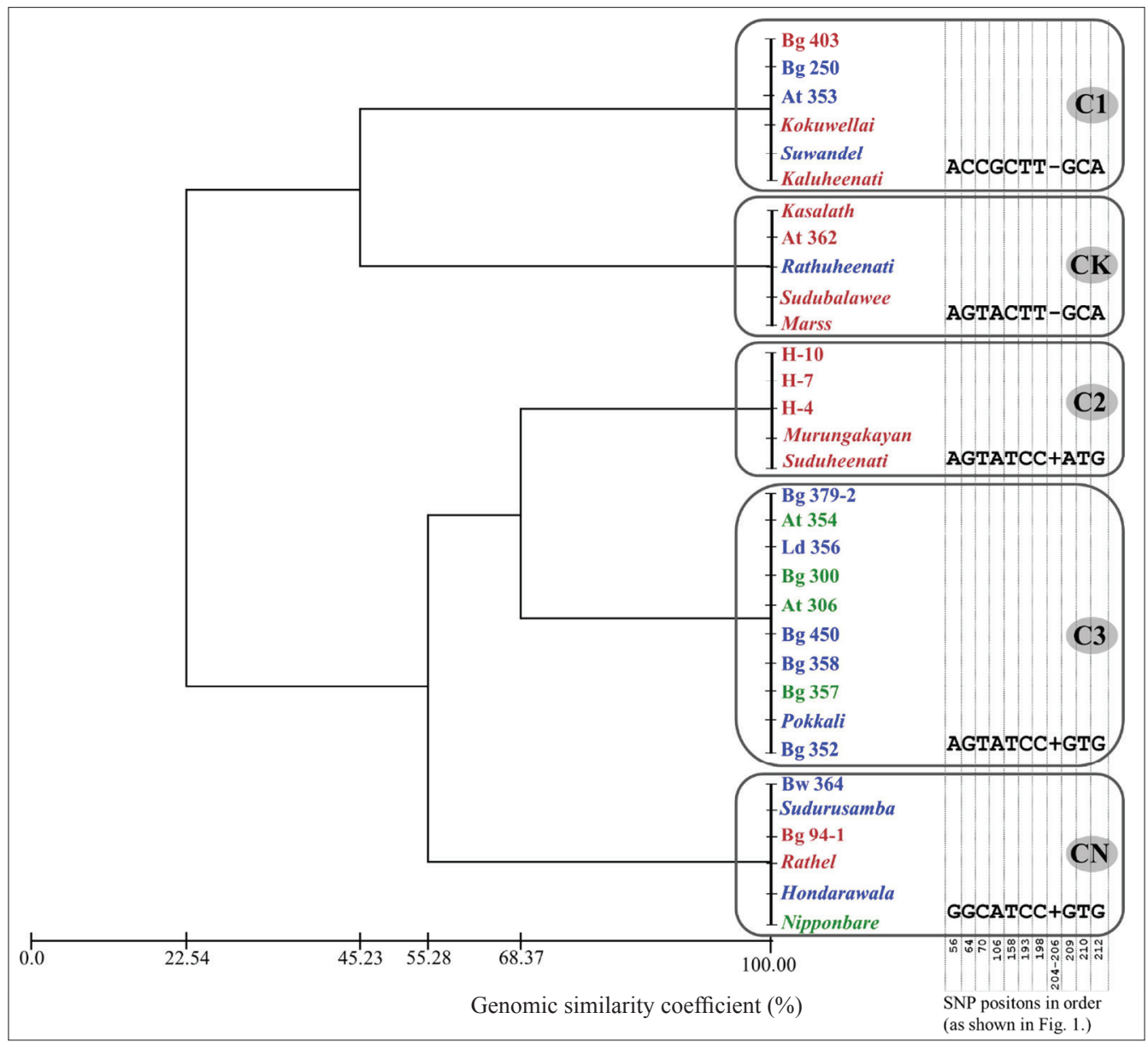

Figure 3: The dendrogram constructed for 32 rice genotypes based on the ten SNPs and the INDEL mutation detected in the K20-1 genomic region 
and breeding as well. The K20-1 sequences and their identical by descent with respect to the available pedigree relationship and overall PD tolerance level (Aluwihare et al., 2016) were displayed using Pedimap software (Figure 4). Since pedigree relationships are not available for most of the genotypes within the 30 genotypes studied, the identical by descent was shown only for a few genotypes. The pedigree structure revealed the distribution of the degree of PD tolerance across all the genotypes. Brown colour in Kasalath represents maximum tolerance, and green colour in Nipponbare represents maximum sensitivity. The haplotypes of the unrelated individuals in the illustration were assigned with unique colours by Pedimap. But the related individuals are shown with combined colours and the IBD of the haplotypes are also included. For example, At 354 has Pokkali and Bg 94-1 as parents but the K20-1 region of At 354 has been inherited from Pokkali. At 353 might have received its haplotype from the unknown parent while $\mathrm{Bg} 94-1$ is the male parent. H-4, a RIL from the cross between Murungakayan and Marss, is the highest tolerant variety according to Aluwihare

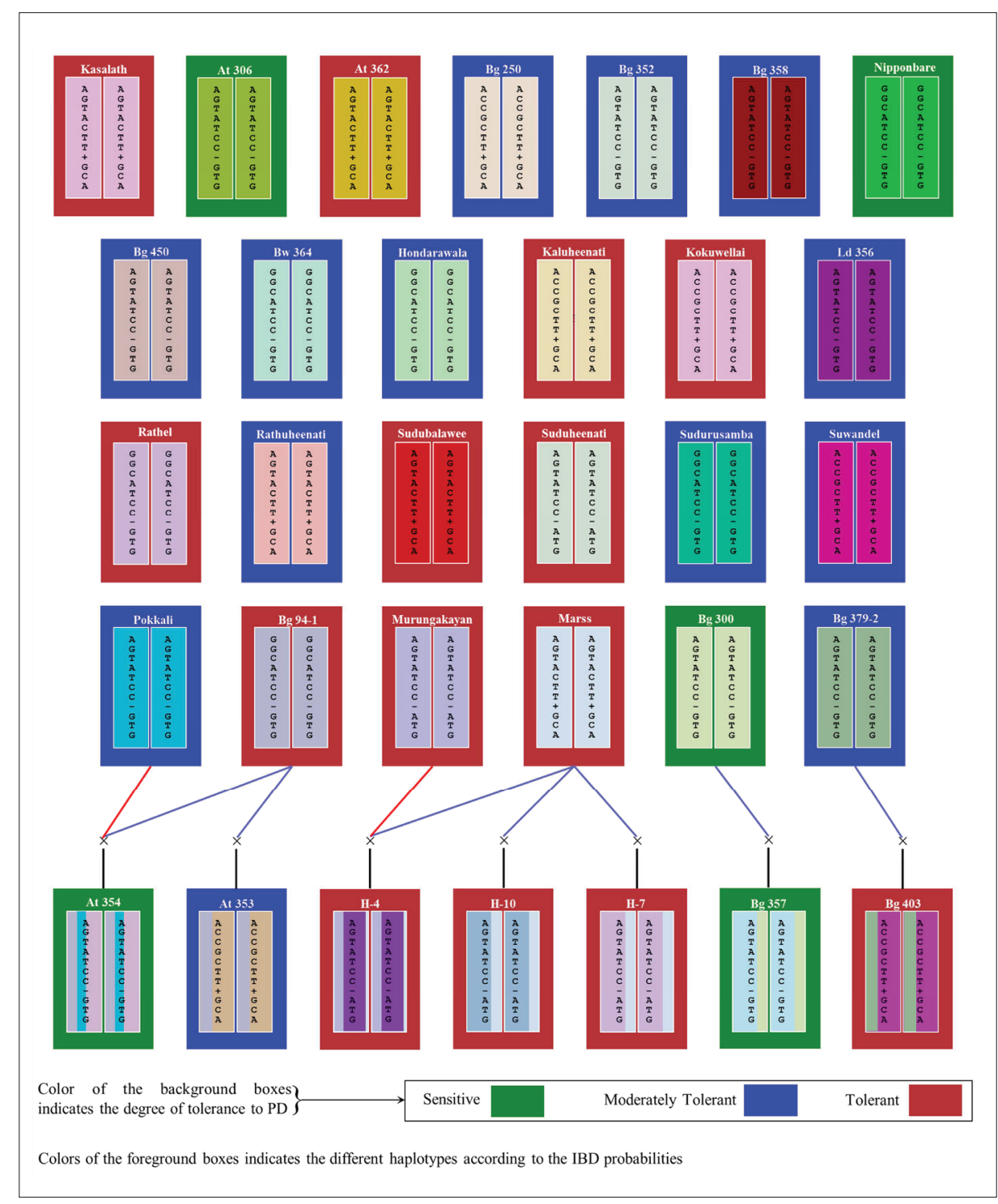

Figure 4: Visualisation of the PD tolerance score, K20-1 SNP haplotypes and available pedigree relationships in 32 rice genotypes [redrawn using the output created by Pedimap software (Voorrips, 2007)] 
et al. (2016), and has received its haplotype from the female parent Murungakayan. The genotypes At 353, $\mathrm{H}-10, \mathrm{H}-7, \mathrm{Bg} 357$ and Bg 403, which have only one parent in the current set clearly displayed the parental origin of haplotypes. Although the female parent of H-7 and $\mathrm{H}-10$ are not included in this study it was a sister RIL of H-4 named H-5 that should have received K20-1 haplotype from the parental landrace Murungakayan. The genotypes $\mathrm{Bg} 357$ and $\mathrm{Bg} 403$ received their K20-1 haplotypes from the paternal parent. The colour depiction of PD tolerance in 32 rice genotypes clearly explains the differential tolerance or sensitivity towards PD (Figure 4). Attempts are in place to convert the conventionally recorded pedigree relationships, trait values and available marker and sequence information as Pedimap based visual displays to facilitate rice breeding in Sri Lanka.

\section{Association analysis}

The association analyses conducted using TASSEL 5 software revealed that SNPs and INDEL alleles are associated with PD tolerance related traits. $\mathrm{PlH}$ measured under $\mathrm{P}_{0}$ and $\mathrm{P}_{30}$ conditions was strongly associated with the SNP located at $209^{\text {th }}$ base position $(p<0.05)$. In this SNP, when the allele 'A' was in homozygous condition (which could only be seen in some Sri Lankan rice genotypes), plants were taller than the plants which has homozygous ' $\mathrm{G}$ '. The NT was significantly associated with the eight SNPs and the INDEL $(\mathrm{p}<0.05)$ (Table 3).

The only significant marker trait association for SDW was with the SNP at $209^{\text {th }}$ position $(p<0.05)$. In homozygous 'A' class, the mean SDW was $23.82 \mathrm{~g}$ compared to mean SDW of $14.83 \mathrm{~g}$ in homozygous ' $\mathrm{G}$ ' class $(\mathrm{p}<0.05)$. Five SNPs and the INDEL were strongly associated with SPC and PUE. Only the SNP at $209^{\text {th }}$ position was significantly associated with SPU $(p<0.1)$. The overall score of PD tolerance was associated with six SNPs $\left(158^{\text {th }}, 193^{\text {rd }}, 198^{\text {th }}, 209^{\text {th }}, 210^{\text {th }}\right.$ and $212^{\text {th }}$ positions $)$ and the INDEL $(\mathrm{p}<0.05)$ (Table 3$)$.

In summary, the classical approach was followed in the Pupl QTL mapping studies in which the linkage relationship between markers and traits are considered (Wissuwa et al., 1998; Wissuwa, 2003). However, no particular attention has been given to find the significant association between the SNPs and INDELs with the PD tolerance traits. In the present study, we report the association between PD tolerance traits and SNPs/ INDEL of the K20-1 region from a selected set of rice germplasm. It would be interesting to see an important core-collection of rice genotypes with varieties, mapping populations, unreleased breeding materials produced
Table 2: GenBank accession numbers of the K20-1 DNA sequences of the rice genotypes

\begin{tabular}{ll}
\hline Name of the genotype & GenBank accession number \\
\hline Hondarawala & KU174163 \\
Rathel & KU174164 \\
Bg 94-1 & KU174174 \\
Sudurusamba & KU174175 \\
Bw 364 & KU174176 \\
Bg 352 & KU174169 \\
Pokkali & KU174166 \\
Bg 357 & KU174170 \\
Bg 358 & KU174171 \\
Bg 450 & KU174173 \\
At 306 & KU174178 \\
Bg 300 & KU174179 \\
Ld 356 & KU174182 \\
At 354 & KU174184 \\
Bg 379-2 & KU174186 \\
Murungakayan & KU174158 \\
Suduheenati & KU174159 \\
H-4 & KU174168 \\
H-7 & KU174177 \\
H-10 & KU174181 \\
Marss & KU174157 \\
Sudubalawee & KU174162 \\
Rathuheenati & KU174165 \\
At 362 & KU174185 \\
Kaluheenati & KU174160 \\
Suwandel & KU174161 \\
Kokuwellai & KU174167 \\
At 353 & KU174172 \\
Bg 250 & KU174180 \\
Bg 403 & \\
\hline & \\
\hline &
\end{tabular}

Source : http://www.ncbi.nlm.nih.gov/

from the original varieties and landraces are subjected to a meta-association analysis of the DNA sequence polymorphism and the traits. With the present study, we proved that Kasalath type K20-1 haplotype is associated with PD tolerance but another haplotype, which is probably specific to Sri Lankan germplasm also confers a higher tolerance. We propose that these two haplotypes could be used in MAB of rice for PD tolerance. However, the reliance on K20-1 PCR followed by SduI (Bsp 1286I) or MseI digestion to evaluate the polymorphism as a CAP maker is doubtful because the highest PD tolerant genotypes in the present study (the ones in $\mathrm{C} 2$ cluster) (Figure 3) do not have these palindromic sequences within the K20-1 region. Therefore, we propose an alternative strategy of employing an allele specific oligonucleotide assay to detect the ' $A$ ' allele along with 
the SduI (Bsp 1286I) and MseI digestion, to discriminate the tolerant genotypes from the sensitive ones in MAB or marker assisted seedling selection (MASS). These kinds of CAP markers and allele specific oligonucleotide assays are common in human, mouse and plant genetic and breeding studies (Saiki et al., 1985; Hixson \& Vernier, 1990; Gutierrez et al., 2006). The establishment of simple and easier genotyping strategies of MAB is essential (Sofi \& Rather, 2007; Pérez-de-Castro, 2012) and they should not be completely depending on the routine DNA sequencing and the hectic downstream bioinformatic analysis (Asins, 2002; Collard \& Mackill, 2008). However, more in-depth sequence analyses of the entire Pup1 QTL region with a larger germplasm panel would provide a deeper insight to mine more novel haplotypes that could be used in MAB for PD tolerance.

\section{CONCLUSION}

The DNA sequence analyses of K20-1 region of the 30 rice genotypes revealed that PD tolerance is not only conferred by the Kasalath type sequence haplotype but also by another haplotype, which is present in the landrace Murungakayan and some of the old improved varieties in Sri Lanka. The DNA sequence polymorphisms within the K20-1 region was further expanded by the current study compared to what is reported in Chin et al. (2011) envisaging the fact that meta-analysis of the DNA sequence polymorphism within the entire Pupl region of the important genotypes of the rice germplasm is essential to layout a precise and accurate haplotype based MAB strategy to produce PD tolerant rice genotypes for the diverse requirements in global rice industry.

Table 3: Association of PD tolerance related traits with the SNPs and the INDEL detected in K20-1 STS region

\begin{tabular}{|c|c|c|c|c|c|c|c|}
\hline Trait & Growing condition $^{\mathrm{a}}$ & Locus (bp) $)^{b}$ & Alleles ${ }^{c}$ & Mean LL & Mean RR & GS & $P$ value \\
\hline \multirow[t]{5}{*}{$\mathrm{PlH}$} & $\mathrm{P}_{0}-\mathrm{GH}-M a h a$ & 209 & $\mathrm{~A} / \mathrm{G}$ & 96.17 & 69.43 & 26.74 & $2.28 \mathrm{E}-04$ \\
\hline & $\mathrm{P}_{30}-\mathrm{GH}-$ Yala & 209 & $\mathrm{~A} / \mathrm{G}$ & 77.81 & 53.17 & 24.64 & 5.37E-06 \\
\hline & $\mathrm{P}_{0}-\mathrm{F}-$ Yala & 209 & $\mathrm{~A} / \mathrm{G}$ & 82.10 & 62.95 & 19.15 & 0.033 \\
\hline & $\mathrm{P}_{30}-\mathrm{GH}-$ Maha & 209 & $\mathrm{~A} / \mathrm{G}$ & 91.91 & 73.24 & 18.67 & 0.003 \\
\hline & $\mathrm{P}_{0}-\mathrm{GH}-$ Yala & 209 & $\mathrm{~A} / \mathrm{G}$ & 88.04 & 58.72 & 29.32 & $6.70 \mathrm{E}-05$ \\
\hline \multirow[t]{18}{*}{ NT } & $\mathrm{P}_{0}-\mathrm{F}-$ Yala & 106 & $\mathrm{~A} / \mathrm{G}$ & 2.28 & 3.20 & -0.92 & 0.004 \\
\hline & $\mathrm{P}_{30}-\mathrm{GH}-$ Yala & 106 & $\mathrm{~A} / \mathrm{G}$ & 3.99 & 6.44 & -2.45 & 0.021 \\
\hline & $\mathrm{P}_{0}-\mathrm{F}-$ Yala & 158 & $\underline{\mathrm{C}} / \mathrm{T}$ & 3.20 & 2.28 & 0.92 & 0.004 \\
\hline & $\mathrm{P}_{30}-\mathrm{GH}-$ Yala & 158 & $\underline{\mathrm{C}} / \mathrm{T}$ & 6.44 & 3.99 & 2.45 & 0.021 \\
\hline & $\mathrm{P}_{0}-\mathrm{F}-$ Yala & 193 & $\mathrm{C} / \underline{\mathrm{T}}$ & 2.28 & 3.20 & -0.92 & 0.004 \\
\hline & $\mathrm{P}_{30}-\mathrm{GH}-$ Yala & 193 & $\mathrm{C} / \underline{\mathrm{T}}$ & 3.99 & 6.44 & -2.45 & 0.021 \\
\hline & $\mathrm{P}_{0}-\mathrm{F}-$ Yala & 198 & $\mathrm{C} / \underline{\mathrm{T}}$ & 2.28 & 3.20 & -0.92 & 0.004 \\
\hline & $\mathrm{P}_{30}-\mathrm{GH}-$ Yala & 198 & $\mathrm{C} / \underline{\mathrm{T}}$ & 3.99 & 6.44 & -2.45 & 0.021 \\
\hline & $\mathrm{P}_{0}-\mathrm{F}-$ Yala & $204-206$ & $+1 z^{d}$ & 2.28 & 3.20 & -0.92 & 0.004 \\
\hline & $\mathrm{P}_{30}-\mathrm{GH}-$ Yala & $204-206$ & $+/ z^{d}$ & 3.99 & 6.44 & -2.45 & 0.021 \\
\hline & $\mathrm{P}_{0}-\mathrm{F}-$ Yala & 210 & $\underline{\mathrm{C}} / \mathrm{T}$ & 3.20 & 2.28 & 0.92 & 0.004 \\
\hline & $\mathrm{P}_{30}-\mathrm{GH}-$ Yala & 210 & $\underline{\mathrm{C}} / \mathrm{T}$ & 6.44 & 3.99 & 2.45 & 0.021 \\
\hline & $\mathrm{P}_{0}-\mathrm{F}-$ Yala & 212 & $\underline{\mathrm{A}} / \mathrm{G}$ & 3.20 & 2.28 & 0.92 & 0.004 \\
\hline & $\mathrm{P}_{30}-\mathrm{GH}-$ Yala & 212 & $\underline{\mathrm{A}} / \mathrm{G}$ & 6.44 & 3.99 & 2.45 & 0.021 \\
\hline & $\mathrm{P}_{0}-\mathrm{F}-$ Yala & 64 & $\mathrm{C} / \mathrm{G}$ & 3.20 & 2.28 & 0.92 & 0.004 \\
\hline & $\mathrm{P}_{30}-\mathrm{GH}-$ Yala & 64 & $\mathrm{C} / \mathrm{G}$ & 6.44 & 3.99 & 2.45 & 0.021 \\
\hline & $\mathrm{P}_{0}-\mathrm{F}-$ Yala & 70 & $\mathrm{~d} / \mathrm{T}$ & 3.20 & 2.28 & 0.92 & 0.004 \\
\hline & $\mathrm{P}_{30}-\mathrm{GH}-$ Yala & 70 & $\mathrm{~d} / \mathrm{T}$ & 6.44 & 3.99 & 2.45 & 0.021 \\
\hline SDW & $\mathrm{P}_{0}-\mathrm{GH}-$ Maha & 209 & $\mathrm{~A} / \mathrm{G}$ & 23.82 & 14.83 & 9.49 & $3.54 \mathrm{E}-04$ \\
\hline \multirow[t]{6}{*}{$\mathrm{SPC}$} & $\mathrm{P}_{0}-\mathrm{F}-$ Maha & 158 & $\underline{\mathrm{C}} / \mathrm{T}$ & 0.54 & 0.68 & -0.14 & 0.071 \\
\hline & $\mathrm{P}_{0}-\mathrm{F}-M a h a$ & 193 & $\mathrm{C} / \underline{\mathrm{T}}$ & 0.68 & 0.54 & 0.14 & 0.071 \\
\hline & $\mathrm{P}_{0}-\mathrm{F}-M a h a$ & 198 & $\mathrm{C} / \underline{\mathrm{T}}$ & 0.68 & 0.54 & 0.14 & 0.071 \\
\hline & $\mathrm{P}_{0}-\mathrm{F}-$ Maha & $204-206$ & $+/ z^{d}$ & 0.68 & 0.54 & 0.14 & 0.071 \\
\hline & $\mathrm{P}_{0}-\mathrm{F}-M a h a$ & 210 & $\underline{\mathrm{C}} / \mathrm{T}$ & 0.54 & 0.68 & -0.14 & 0.071 \\
\hline & $\mathrm{P}_{0}-\mathrm{F}-M a h a$ & 212 & $\underline{\mathrm{A}} / \mathrm{G}$ & 0.54 & 0.68 & -0.14 & 0.071 \\
\hline \multirow[t]{2}{*}{ SPU } & $\mathrm{P}_{0}-\mathrm{GH}-M a h a$ & 209 & $\mathrm{~A} / \mathrm{G}$ & 12.96 & 9.76 & 3.19 & 0.059 \\
\hline & $\mathrm{P}_{30}-\mathrm{GH}-$ Yala & 209 & $\mathrm{~A} / \mathrm{G}$ & 19.34 & 14.83 & 4.50 & 0.064 \\
\hline
\end{tabular}


continued from page 422

\begin{tabular}{|c|c|c|c|c|c|c|c|}
\hline Trait & Growing condition ${ }^{\mathrm{a}}$ & Locus $(b p)^{b}$ & Alleles ${ }^{c}$ & Mean LL & Mean RR & GS & $\mathrm{P}$ value \\
\hline \multirow[t]{6}{*}{ PUE } & $\mathrm{P}_{0}-\mathrm{F}-\mathrm{Maha}$ & 158 & $\underline{\mathrm{C}} / \mathrm{T}$ & 1.94 & 1.54 & 0.40 & 0.058 \\
\hline & $\mathrm{P}_{0}-\mathrm{F}-\mathrm{Maha}$ & 193 & $\mathrm{C} / \underline{\mathrm{T}}$ & 1.54 & 1.94 & -0.40 & 0.058 \\
\hline & $\mathrm{P}_{0}-\mathrm{F}-\mathrm{Maha}$ & 198 & $\mathrm{C} / \underline{\mathrm{T}}$ & 1.54 & 1.94 & -0.40 & 0.058 \\
\hline & $\mathrm{P}_{0}-\mathrm{F}-\mathrm{Maha}$ & 204-206 & $+/ z^{d}$ & 1.55 & 1.94 & -0.39 & 0.058 \\
\hline & $\mathrm{P}_{0}-\mathrm{F}-\mathrm{Maha}$ & 210 & $\underline{\mathrm{C}} / \mathrm{T}$ & 1.94 & 1.55 & 0.39 & 0.058 \\
\hline & $\mathrm{P}_{0}-\mathrm{F}-\mathrm{Maha}$ & 212 & $\underline{\mathrm{A}} / \mathrm{G}$ & 1.94 & 1.54 & 0.40 & 0.058 \\
\hline \multirow[t]{7}{*}{ PDT } & $\mathrm{P}_{0}-\mathrm{GH}-\mathrm{Maha}$ & 158 & $\underline{\mathrm{C}} / \mathrm{T}$ & 2.63 & 2.10 & 0.53 & 0.044 \\
\hline & $\mathrm{P}_{0}-\mathrm{GH}-\mathrm{Maha}$ & 193 & $\mathrm{C} / \underline{\mathrm{T}}$ & 2.10 & 2.64 & -0.54 & 0.044 \\
\hline & $\mathrm{P}_{0}-\mathrm{GH}-\mathrm{Maha}$ & 198 & $\mathrm{C} / \underline{\mathrm{T}}$ & 2.10 & 2.64 & -0.54 & 0.044 \\
\hline & $\mathrm{P}_{0}-\mathrm{GH}-\mathrm{Maha}$ & $204-206$ & $+/=^{d}$ & 2.10 & 2.64 & -0.54 & 0.044 \\
\hline & $\mathrm{P}_{0}-\mathrm{GH}-M a h a$ & 209 & $\mathrm{~A} / \mathrm{G}$ & 3.00 & 2.14 & 0.86 & 0.013 \\
\hline & $\mathrm{P}_{0}-\mathrm{GH}-\mathrm{Maha}$ & 210 & $\underline{\mathrm{C}} / \mathrm{T}$ & 2.64 & 2.10 & 0.54 & 0.044 \\
\hline & $\mathrm{P}_{0}-\mathrm{GH}-M a h a$ & 212 & $\underline{\mathrm{A}} / \mathrm{G}$ & 2.64 & 2.10 & 0.54 & 0.044 \\
\hline
\end{tabular}

a The growing condition represent the $\mathrm{P}$ level supplied $\left(\mathrm{P}_{0}: 1 \mathrm{mg}\right.$ of $\mathrm{P}$ in $1 \mathrm{~kg}$ of soil and $\mathrm{P}_{30}: 30 \mathrm{mg}$ of $\mathrm{P}_{2} \mathrm{O}_{5}$ was added to $1 \mathrm{~kg}$ of Ultisol soil) and greenhouse (GH) or field (F) conditions used. Yala and Maha represent the two general cropping seasons in Sri Lanka

${ }^{\text {b }}$ The base position within the K20-1 STS region which has the total length of 240 or 243 bp (Figure 1)

${ }^{c}$ The SNP or INDEL alleles detected in each locus. Only biallelic SNPs are detected

${ }^{\mathrm{d}} \mathrm{CAG}$ insertion can be seen in 11 rice genotypes at the position 204 bp to $206 \mathrm{bp}$

Mean LL represent the mean phenotype when the allele shown in the left side of the SNP column are in homozygous condition. Mean RR represent the mean phenotype when the allele shown in the right side of the SNP column are in homozygous condition. GS designates the gain of selection which is calculated by subtracting the mean RR by mean LL. P value indicates the probability level for significant mean differences calculated using Tassel 5.0 software. Alleles shown with white colour font in black background are present only in Sri Lankan rice germplasm. Alleles shown in gray background are present in both Kasalath, Nipponbare and some of the Sri Lankan rice genotypes. Alleles underlined are present in Kasalath and some of the Sri Lankan genotypes. Alleles not underlined are present in Nipponbare and some of the Sri Lankan genotypes. SDW: shoot dry weight (grams per pot); SPC: shoot P concentration [amount of P (mg) in 1 gram of shoot dry]; SPU: shoot P uptake (mg P per pot); PUE: P utilisation efficiency (biomass produced per unit P accumulated in shoot tissue); PDT: P deficiency tolerance score assigned in Aluwihare et al. (2016).

\section{Acknowledgement}

The authors wish to acknowledge the National Research Council (NRC), Sri Lanka (Grant No: NRC 11-087) for financial assistance.

\section{REFERENCES}

1. Aluwihare Y.C., Ishan M., Chamikara M.D.M., Weebadde C.K., Sirisena D.N., Samarasinghe W.L.G. \& Sooriyapathirana S.D.S.S. (2016). Characterization and selection of phosphorus deficiency tolerant rice genotypes in Sri Lanka. Rice Science 23(4): 184 - 195.

DOI: https://doi.org/10.1016/j.rsci.2015.10.001

2. Asins M. (2002). Present and future of quantitative trait locus analysis in plant breeding. Plant Breeding 121: 281 $-291$.

DOI: https://doi.org/10.1046/j.1439-0523.2002.730285.x

3. Bennett E.M., Carpenter S.R. \& Caraco N.F. (2001). Human impact on erodable phosphorus and eutrophication: a global perspective increasing accumulation of phosphorus in soil threatens rivers, lakes, and coastal oceans with eutrophication. BioScience 51: 227 - 234.

4. Bradbury P.J., Zhang Z., Kroon D.E., Casstevens T.M., Ramdoss Y. \& Buckler E.S. (2007). TASSEL 5: software for association mapping of complex traits in diverse samples. Bioinformatics 23: 2633 - 2635.

DOI: https://doi.org/10.1093/bioinformatics/btm308

5. Chandrajith R., Seneviratna S., Wickramaarachchi K., Attanayake T., Aturaliya T.N.C. \& Dissanayake C.B. (2010). Natural radionuclides and trace elements in rice field soils in relation to fertilizer application: study of a chronic kidney disease area in Sri Lanka. Environmental Earth Sciences 60(1): 193 - 201.

DOI: https://doi.org/10.1007/s12665-009-0179-1

6. Chin J.H., Gamuyao R., Dalid C., Bustamam M., Prasetiyono J., Moeljopawiro S., Wissuwa M. \& Heuer S. (2011). Developing rice with high yield under phosphorus deficiency: Pup1 sequence to application. Plant Physiology 156(3): $1202-1216$.

DOI: https://doi.org/10.1104/pp.111.175471

7. Chin J.H., Lu X., Haefele H.M., Gamuyao R., Ismail A.M., Heuer S. \& Wissuwa M. (2010). Development and application of gene-based markers for the major rice QTL phosphorus uptake 1. Theoretical and Applied Genetics 
120(6): $1073-1086$.

DOI: https://doi.org/10.1007/s00122-009-1235-7

8. Collard B.C.Y. \& Mackill D.J. (2008). Marker-assisted selection: an approach for precision plant breeding in the twenty-first century. Philosophical Transactions of the Royal Society B: Biological Sciences 363: 557 - 572.

DOI: https://doi.org/10.1098/rstb.2007.2170

9. Cordell D., Drangert J.O. \& White S. (2009). The story of phosphorus: global food security and food for thought. Global Environmental Change 19: 292 - 305.

DOI: https://doi.org/10.1016/j.gloenvcha.2008.10.009

10. Department of Agriculture (DoA) (2006a). Climate of Rice Growing Regions in Sri Lanka. Department of Agriculture, Sri Lanka. Available at http://www.agridept.gov.lk/. Accessed 17 October 2016.

11. Department of Agriculture (DoA) (2006b). Recommended Varieties Released List. Department of Agriculture, Sri Lanka. Available at http://www.agridept.gov.lk/. Accessed 17 October 2016.

12. Ducrocq S., Giauffret C., Madur D., Combes V., Dumas F., Jouanne S., Coubriche D., Jamin P., Moreau L. \& Charcosset A. (2009). Fine mapping and haplotype structure analysis of a major flowering time quantitative trait locus on maize chromosome 10. Genetics 183(4): 1555 - 1563.

DOI: https://doi.org/10.1534/genetics.109.106922

13. Fageria N.K., Filho M.P.B. \& Carvalho J.R.P. (1982). Response of upland rice to phosphorus fertilization on an oxisol of central Brazil. Agronomy Journal 74: 51 - 56.

14. Fageria N.K., Wright R.J. \& Baligar V.C. (1988). Rice cultivar evaluation for phosphorus use efficiency. Plant and Soil Science 111(1): 105 - 109.

DOI: https://doi.org/10.1007/BF02182043

15. Gamuyao R., Chin J.H., Pariasca-Tanaka J., Pesaresi P., Catausan S., Dalid C., Slamet-Loedin I., Tecson-Mendoza E.M., Wissuwa M. \& Heuer S. (2012). The protein kinase Pstoll from traditional rice confers tolerance of phosphorus deficiency. Nature 488: 535 - 539.

DOI: https://doi.org/10.1038/nature11346

16. Gunes A., Inal A., Alpaslan M. \& Cakmak I. (2006). Genotypic variation in phosphorus efficiency between wheat cultivars grown under greenhouse and field conditions. Soil Science and Plant Nutrition 52(4): $470-$ 478.

DOI: https://doi.org/10.1111/j.1747-0765.2006.00068.x

17. Gutierrez N., Avila C.M., Duc G., Marget P., Suso M.J., Moreno M.T. \& Torres A.M. (2006). CAPs markers to assist selection for low vicine and convicine contents in faba bean (Vicia faba L.). Theoretical and Applied Genetics 114(1): $59-66$.

DOI: https://doi.org/10.1007/s00122-006-0410-3

18. Hanson W.C. (1950). The photometric determination of phosphorus in fertilizers using the phosphovanadomolybdate complex. Journal of the Science of Food and Agriculture 1: 172 - 173.

DOI: https://doi.org/10.1002/jsfa.2740010604

19. He G. et al. (11 authors) (2006). Haplotype variation in structure and expression of a gene cluster associated with a quantitative trait locus for improved yield in rice. Genome Research 16(5): $618-626$.
DOI: https://doi.org/10.1101/gr.4814006

20. Hedley M.J., Kirk G.J.D. \& Santos M.B. (1994). Phosphorus deficiency and the forms of soil phosphorus utilized by upland rice cultivars. Plant and Soil 158: 53 - 62 . DOI: https://doi.org/10.1007/BF00007917

21. Heuer S. et al. (11 authors) (2009). Comparative sequence analyses of the major quantitative trait locus phosphorus uptake 1 (Pup1) reveal a complex genetic structure. Plant Biotechnology Journal 7(5): 456 - 471. DOI: https://doi.org/10.1111/j.1467-7652.2009.00415.x

22. Hixson J.E. \& Vernier D.T. (1990). Restriction isotyping of human apolipoprotein $\mathrm{E}$ by gene amplification and cleavage with HhaI. The Journal of Lipid Research 31(3): $545-548$.

23. Ismail A.M., Heuer S., Thomson M.J. \& Wissuwa M. (2007). Genetic and genomic approaches to develop rice germplasm for problem soils. Plant Molecular Biology 65(4): $547-570$.

DOI: https://doi.org/10.1007/s11103-007-9215-2

24. Jiao W., Chen W., Chang A.C. \& Page A.L. (2012). Environmental risks of trace elements associated with long-term phosphate fertilizers applications: a review. Environmental Pollution 168: 44 - 53.

DOI: https://doi.org/10.1016/j.envpol.2012.03.052

25. Kirk G.J.D., George T., Courtois B. \& Senadhira D. (1998). Opportunities to improve phosphorus efficiency and soil fertility in rain fed lowland and upland rice ecosystems. Field Crops Research 56: 73 - 92.

26. Kumaragamage D. \& Indraratne S. (2011). Systemic approach to diagnosing fertility problems in soils of Sri Lanka. Communications in Soil Science and Plant Analysis 42(22): $2699-2715$.

DOI: https://doi.org/10.1080/00103624.2011.622818

27. Lang N.T. \& Buu B.C. (2006). Mapping QTLs for phosphorus deficiency tolerance in rice (Oryza sativa L.). Omonrice 14: 1 - 9 .

28. Li L., Qiu X., Li X., Wang S. \& Lian X. (2009). The expression profile of genes in rice roots under low phosphorus stress. Science in China Series C: Life Sciences 52(11): 1055 - 1064.

DOI: https://doi.org/10.1007/s11427-009-0137-x

29. Li Y. et al. (11 authors) (2012). Comparative LD mapping using single SNPs and haplotypes identifies QTL for plant height and biomass as secondary traits of drought tolerance in maize. Molecular Breeding 30(1): 407 - 418. DOI: https://doi.org/10.1007/s11032-011-9631-5

30. Ni J.J., Wu P., Senadhira D. \& Huang N. (1998). Mapping QTLs for phosphorus deficiency tolerance in rice (Oryza sativa L.). Theoretical and Applied Genetics 97: $1361-1369$.

DOI: https://doi.org/10.1007/s001220051030

31. Pariasca-Tanaka J., Chin J.H., Dramé K.N., Dalid C., Heuer S. \& Wissuwa M. (2014). A novel allele of the P-starvation tolerance gene OSPSTOL1 from African rice (Oryza glaberrima Steud) and its distribution in the genus Oryza. Theoretical and Applied Genetics 127: 1387 - 1398. DOI: https://doi.org/10.1007/s00122-014-2306-y

32. Peace C.P., Luby J.J., van de Wag W.E., Bink M.C.A.M. \& Iezzoni A.F. (2014). A strategy for developing 
representative germplasm sets for systematic QTL validation, demonstrated for apple, peach, and sweet cherry. Tree Genetics and Genomes 10(6): 1679 - 1694. DOI: https://doi.org/10.1007/s11295-014-0788-z

33. Pérez-de-Castro A.M., Vilanova S., Canñizares J., Pascual L., Blanca J.M., Díez M.J., Prohens J. \& Picó B. (2012). Application of genomic tools in plant breeding. Current Genomics 13(3): 179 - 195. DOI: https://doi.org/10.2174/138920212800543084

34. Prasetiyono J., Aswidinnoor H., Moeljopawiro S., Sopandie D. \& Bustamam M. (2010). Identification of polymorphic markers for breeding of rice tolerant to phosphorus deficiency. Indonesian Journal of Agriculture 3(1): 1 - 8 .

35. Rose T.J. \& Wissuwa M. (2012). Rethinking internal phosphorus utilization efficiency: a new approach is needed to improve PUE in grain crops. Advances in Agronomy 116: $186-211$.

DOI: https://doi.org/10.1016/B978-0-12-394277-7.00005-1

36. Rosyara U.R., Bink M.C.A.M., van de Weg E., Zhang G., Wang D., Sebolt A., Dirlewanger E., Quero-Garcia J., Schuster M. \& Iezzoni A.F. (2013). Fruit size QTL identification and the prediction of parental QTL genotypes and breeding values in multiple pedigreed populations of sweet cherry. Molecular Breeding 32(4): 875 - 887. DOI: https://doi.org/10.1007/s11032-013-9916-y

37. Saiki R.K., Scharf S., Faloona F., Mullis K.B., Horn G.T., Erlich H.A. \& Arnheim N. (1985). Enzymatic amplification of beta-globin genomic sequences and restriction site analysis for diagnosis of sickle cell anemia. Science 230(4732): 1350 - 1354 .

DOI: https://doi.org/10.1126/science. 2999980

38. Sofi P. \& Rather A.G. (2007). QTL analysis in rice improvement: concept, methodology and application. Biotechnology 6(1): 1 - 13 .

DOI: https://doi.org/10.3923/biotech.2007.1.13

39. Tyagi W., Rai M. \& Dohling A. (2012). Haplotype analysis for Pupl locus in rice genotypes of North Eastern and Eastern India to identify suitable donors tolerant to low phosphorus. SABRAO Journal of Breeding and Genetics 44(2): $398-405$.

40. Voorrips R.E. (2007). Pedimap: software for visualization of genetic and phenotypic data in pedigrees. Plant Research International, Wageningen, The Netherlands.

41. Wissuwa M. (2003). How do plants achieve tolerance to phosphorus deficiency: small causes with big effects. Plant Physiology 133: 1947 - 1958.

DOI: https://doi.org/10.1104/pp.103.029306

42. Wissuwa M. (2005). Combining a modelling with a genetic approach in establishing associations between genetic and physiological effects in relation to phosphorus uptake. Plant and Soil 269: 57 - 68 .

DOI: https://doi.org/10.1007/s11104-004-2026-1

43. Wissuwa M. \& Ae N. (2001). Further characterization of two QTLs that increase phosphorus uptake of rice (Oryza sativa L.) under phosphorus deficiency. Plant and Soil 237: $275-286$.

DOI: https://doi.org/10.1023/A:1013385620875

44. Wissuwa M., Gamat G. \& Ismail A.M. (2005). Is root growth under phosphorus deficiency affected by source or sink limitations? Journal of Experimental Botany 56(417): $1943-1950$.

DOI: https://doi.org/10.1093/jxb/eri189

45. Wissuwa M., Wegner J., Ae N. \& Yano M. (2002). Substitution mapping of Pup1: a major QTL increasing phosphorus uptake of rice from a phosphorus-deficient soil. Theoretical and Applied Genetics 105: 890 - 897. DOI: https://doi.org/10.1007/s00122-002-1051-9

46. Wissuwa M., Yano M. \& Ae N. (1998). Mapping of QTLs for phosphorus deficiency tolerance in rice (Oryza sativa L.). Theoretical and Applied Genetics 97(5): 777 - 783. DOI: https://doi.org/10.1007/s001220050955

47. Yi K., Wu Z., Zhou J., Du L., Guo L., Wu Y. \& Wu P. (2005). OsPTF1, a novel transcription factor involved in tolerance to phosphate starvation in rice. Plant Physiology 138: $2087-2096$.

DOI: https://doi.org/10.1104/pp.105.063115 